\title{
Wear rate and surface coating optimization of coconut coir-based polymer using fuzzy logic
}

\author{
S P SRINIVASAN* and L RAAJARAJAN \\ Department of Mechanical Engineering, Rajalakshmi Engineering College, Chennai 602105, India \\ e-mail: spsrini@rediffmail.com
}

MS received 26 August 2015; revised 25 June 2016; accepted 3 August 2016

\begin{abstract}
The use of fuzzy logic for modeling surface parameters of coconut coir-based composite is the focus of this research paper. Natural fiber-polymer composite has been developed by combining coconut coir as a stimulator and polyester as a fixative. This sturdy material is resistant to scratches in the coating process on the surface layer of composite material. The specimen of this composite material is fabricated by different coir fiber and resin content. A polyurethane coating is also applied with varied thickness to give better wear rate and surface coating properties. A fuzzy logic approach is adopted to invent the optimal wear rate and surface coating using coating thickness and fiber content properties. The results indicate the best combinations of coating thickness and its surface roughness of the sandwiches. MATLAB 7 is used in this work.
\end{abstract}

Keywords. Natural fiber-polymer composites; coating; surface properties; fuzzy logic.

\section{Introduction}

Coir fiber reinforced polymer composites have exhibited excellent wear property in a variety of applications for their specific strength and modulus. Natural fiber reinforced thermoplastic composites are gaining popularity in automotive and nonstructural construction applications. Natural fiber composites using several natural fibers such as ramie, sisal, hemp, jute, bamboo, oil palm, and banana fibers as reinforcements instead of glass fibers have been developed. Natural fibers may play an important role in developing biodegradable composites to resolve the current ecological and environmental problems [1]. Coir fiber industry is particularly important in some areas of the developing world. India, mainly the coastal region of Kerala state, produces $60 \%$ of the total world supply of white coir fiber $[1,2]$. Sri Lanka produces $36 \%$ of the total world brown fiber output. Over $50 \%$ of the coir fiber produced annually throughout the world is consumed in the countries of origin, mainly India. The major market for natural fiber reinforced thermoplastic composites is the automobile components industry where they are used as replacement for glass fiber. They are used as trim parts in dashboards, door panels, parcel shelves, seat cushions, backrests, and cabin linings.

Poor compatibility is a major problem with natural composites. This is overcome with various fiber-polymer interface modifications that result in improved performance of the resulting composite. As coconut coir is considered to be an energy absorbent material, it has the potential for use

*For correspondence in composites. Hence, the current work establishes the development of a natural fiber-based polymer composite consisting of coconut coir as invigorate and polyester as fixative, which has sturdy effects against scratches on further coating process on the layer of manufactured specimen. The specimen of the composite material is fabricated by different coir fiber content and resin content, further polyurethane coating (PU) $[1,3]$ is coated with varied thickness to give better wear rate and surface coating properties. PU is widely used in the automotive sector due to fast manufacturing time, and is mainly used for fixing glass fiber mat. The drying and hardening takes place specifically during the PU dispersion due to its water-borne nature [4]. PU is preferred in many sandwich constructions because of the rapid reaction, less weight, and shorter cycle times [5]. A new research to carry out the safe usage against crack growth was suggested [1]. Hence, a fuzzy approach is proposed in this study to predict the various combinations of wear rate and surface coating optimization.

It was revealed that addition of these fibers can reduce thermal conductivity of the sample and yield a lightweight material [6]. To get the uniform part of composite during cure cycle and also to improve the properties an artificial neural network is proposed for speeding up the repetitions [7]. This paper highlights the application of fuzzy logic approach to surface coating issues, and results of fuzzy processing of the various surface roughness measurements (coating thickness and fiber content), whose accuracy depends on the variations of these parameters. A fuzzy controller, developed in MATLAB environment, is presented together with fuzzification and defuzzification. 
Optimal wear rate and surface coating properties are determined with predicted values gathered from experimental data. Michel Tielemans [4] suggests that the coatings of multiple phase are beneficial over conventional homogeneous coatings due to chemical and mechanical resistance applied on melamine-coated MDF panels [8].

\section{Experimental structure-specimen preparation}

Enhancement of the various properties of biofiber composites can be integrated through polymer matrix coating and surface modification. Hence, greater mechanical properties can be achieved due to improved adhesion and polar interactions [9]. Various composite materials are manufactured through the hand lay-up technique. Short coconut coir fibers are reinforced with polyester resin. This coir fiber composite is fabricated with $30 \mathrm{~mm}$ of fiber length as it gives excellent tensile, impact, and flexural strengths. Three types of composite specimens consisting of $35 \%$ fiber with $65 \%$ polyester resin, $25 \%$ fiber with $75 \%$ resin, and $45 \%$ fiber with 55\% resin have been prepared. The designations of various types of composites are given in table 1; the composition is stirred manually to disperse the fibers in the mold. The cast of each composite is cured under a load of nearly $50 \mathrm{~kg}$ for $24 \mathrm{~h}$ before it is removed from the mold. The composites are coated with polyurethane of varied thickness of 60,120 , and $180 \mu \mathrm{m}$. The fabricated composite materials are shown in figure 1 . The image shows the specimen of coir fiber polyester resin composite before and after coating.

\subsection{Surface coating}

Scanning electronic microscope (SEM) images are used study the external morphology and chemical composition [10]. SEM images have been used to study the morphology of biofiber "hair." Surface indentation was identified through a cross section of biofiber using nano indentation technique. This technique is used to check the hardness, elastic modulus, and creep of hair [11]. These SEM images may also be used in material making, and is easier to monitor the crystal structure orientation. An SEM is preferred for its good depth of focus [12]. The bitter pattern and dry colloidal particles on the boundary regions are obtained through SEM. Samples of sizes between $1 \mathrm{~cm}$ and $5 \mu \mathrm{m}$ can be scanned using conventional methods. The surface morphology is evaluated using these techniques, which provide quantitative information of layer thickness.

The surface morphology of the specimen is shown in figure 2. The SEM image represents the thickness of PU coating in coated material by passing $15 \mathrm{kV}$ electric current at a work distance of $12.80 \mathrm{~mm}$, view field of $397 \mu \mathrm{m}$, and SEM magnification of $320 \times$. The SEM images for nano chemical characterization of human hair have been analyzed for its coating parameters [13].

Figure 3 shows the SEM image representing the coating thickness of PU coating in coated material by passing

Table 1. Types of composites.

\begin{tabular}{lccc}
\hline Composites & Invigorate-fixative combination & No. of specimens & Coating thickness \\
\hline $\mathrm{C} 1$ & $35 \%$ Coir fiber & 2 Specimens (before coating and after coating) & Polyurethane coating with 120 $\mu \mathrm{m}$ \\
$\mathrm{C} 2$ & $65 \%$ Polyester resin & & \\
& $25 \%$ Coir fiber & 2 Specimens (before coating and after coating) & Polyurethane coating with $60 \mu \mathrm{m}$ \\
$\mathrm{C} 3$ & $75 \%$ Polyester resin & & \\
& $45 \%$ Coir fiber & 2 Specimens (before coating and after coating) & Polyurethane coating with $180 \mu \mathrm{m}$ \\
& $55 \%$ Polyester resin & & \\
\hline
\end{tabular}

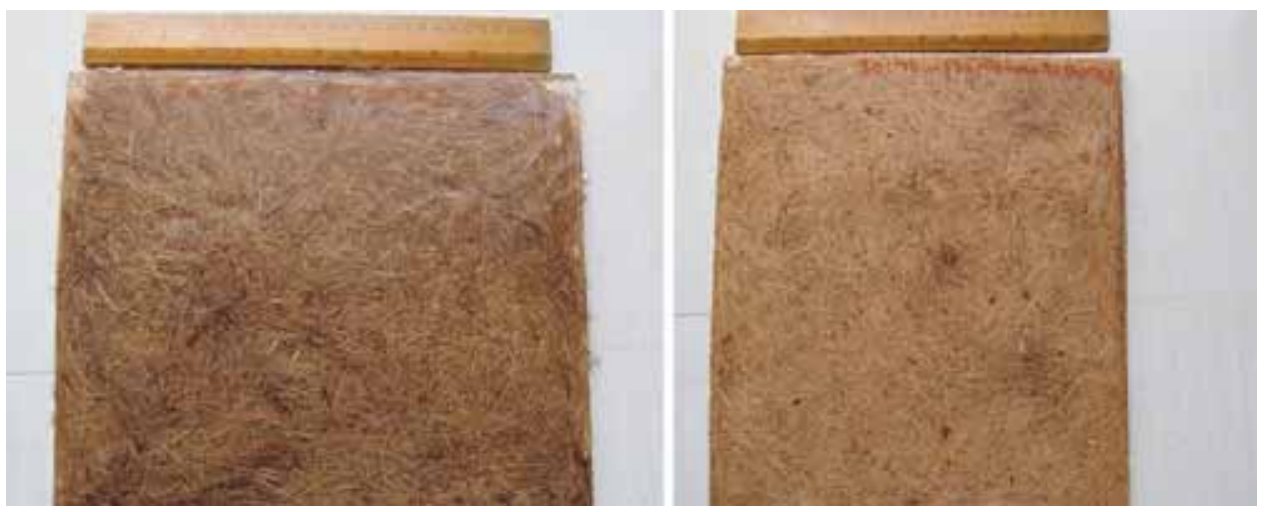

Figure 1. Sample photos of coir fiber-polyester resin composites of uncoated-coated specimen. 


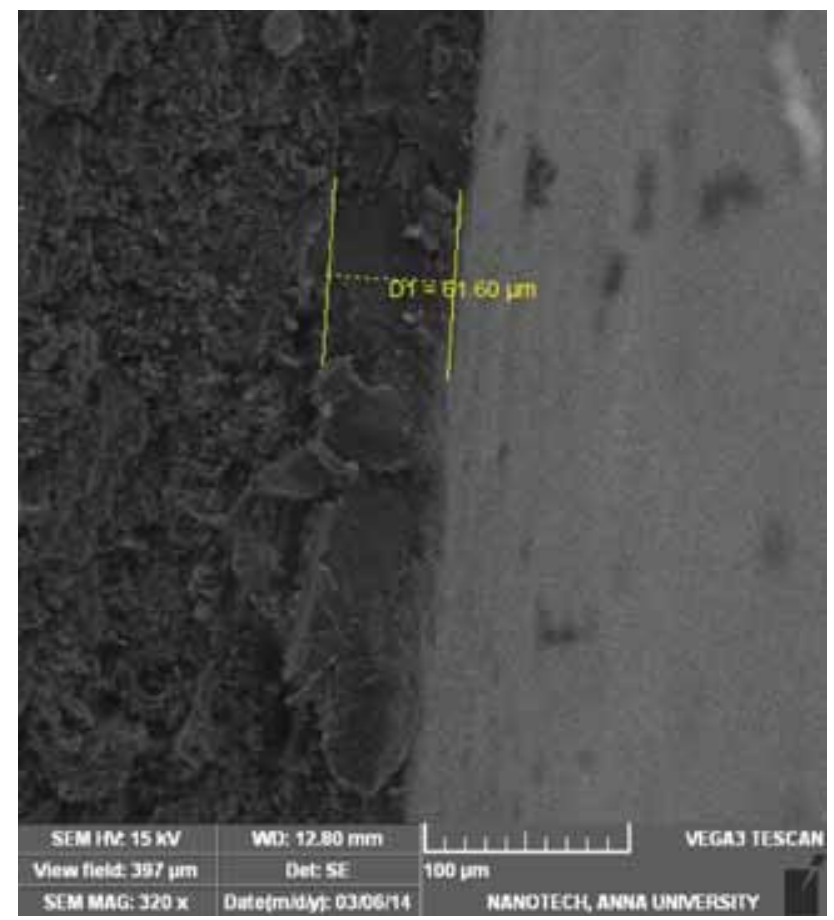

Figure 2. SEM image of PU coating thickness of $60 \mu \mathrm{m}$ in $25: 75$ invigorate-fixative combination.

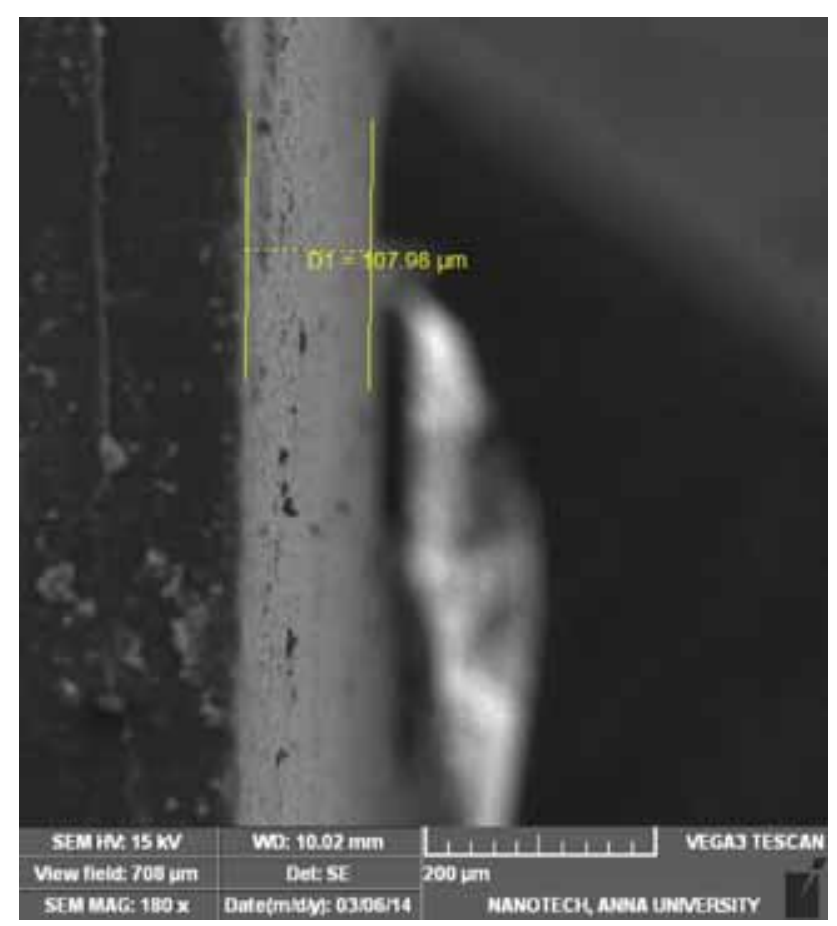

Figure 3. SEM image of PU coating thickness of $120 \mu \mathrm{m}$ in 35:65 invigorate-fixative combination.

$15 \mathrm{kV}$ electric current at a work distance of $10.02 \mathrm{~mm}$, view field of $708 \mu \mathrm{m}$, and SEM magnification of $180 \times$. The surface coating of this sample does not hide the orientation of the surface grains. It is homogeneously

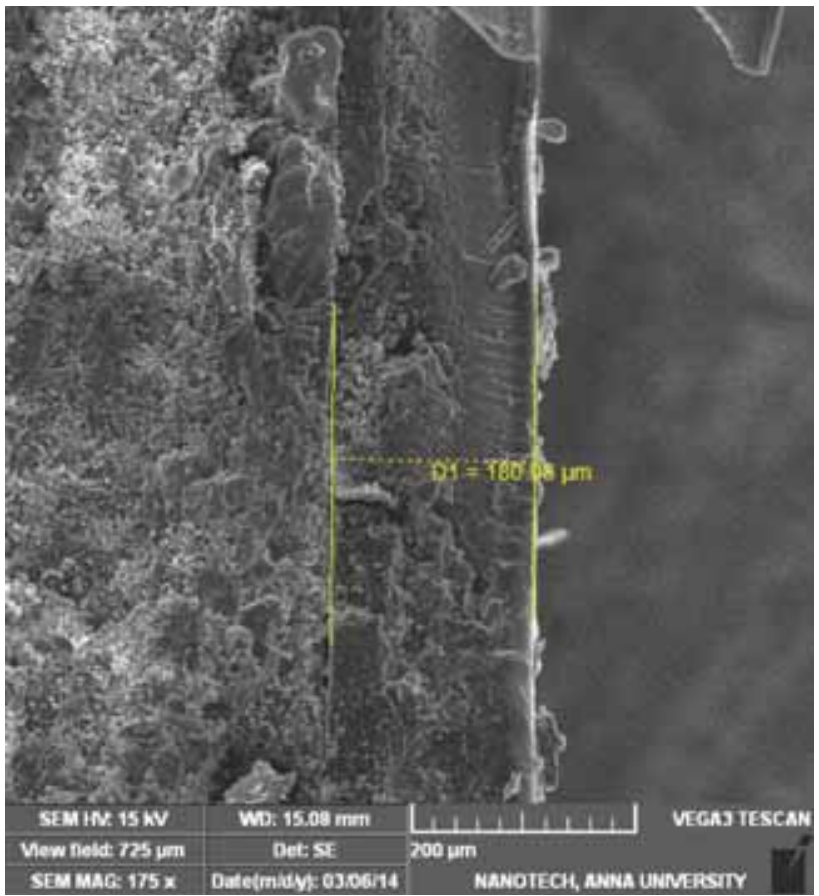

Figure 4. SEM image of PU coating thickness of $180 \mu \mathrm{m}$ on 45:55 invigorate-fixative combination.

distributed and small craters are visualized as shown in figures 2, 3, and 4. These observations show the different morphology of the surface thickness.

Similarly, figure 4 shows an SEM image representing the coating thickness of PU in coated material by passing electric current of $15 \mathrm{kV}$ at the work distance of $15.08 \mathrm{~mm}$, view field of $725 \mu \mathrm{m}$, and SEM magnification of $175 \times$.

This could explain the higher wear rate found at higher fiber content, as illustrated in figure 5. The major material removal takes place at the high surface thickness area. Near to low surface thickness the crack propagates due to maximum stress and microscopic flaw. The coir composite panel contains a deep scratch severing some bends and twists. These deformations predominates the failure of samples at the areas of poor surface thickness and fiber content.

\section{Surface testing and analysis}

To achieve the objective of this experimental work, the specimen is subjected to a wear test. This wear test is being carried out using Pin on Disc Instrument (ASTM G99). Specimen with size of $10 \mathrm{~mm} \times 10 \mathrm{~mm} \times 20 \mathrm{~mm}$ is subjected vertically to the contact area, which is constant. The testing parameters include the load at $9.8 \mathrm{~N}$, speed at $500 \mathrm{rpm}$, sliding distance at $781 \mathrm{~mm} / \mathrm{s}$, time at $15 \mathrm{~min}$, and hardness of disc at 42.8 rockwell hardness (HRC). Hardness of the pin at K scale 79HRK converted to $\mathrm{C}$ scale of $2 \mathrm{HRC}$, Rockwell Hardness. Thus, addition 

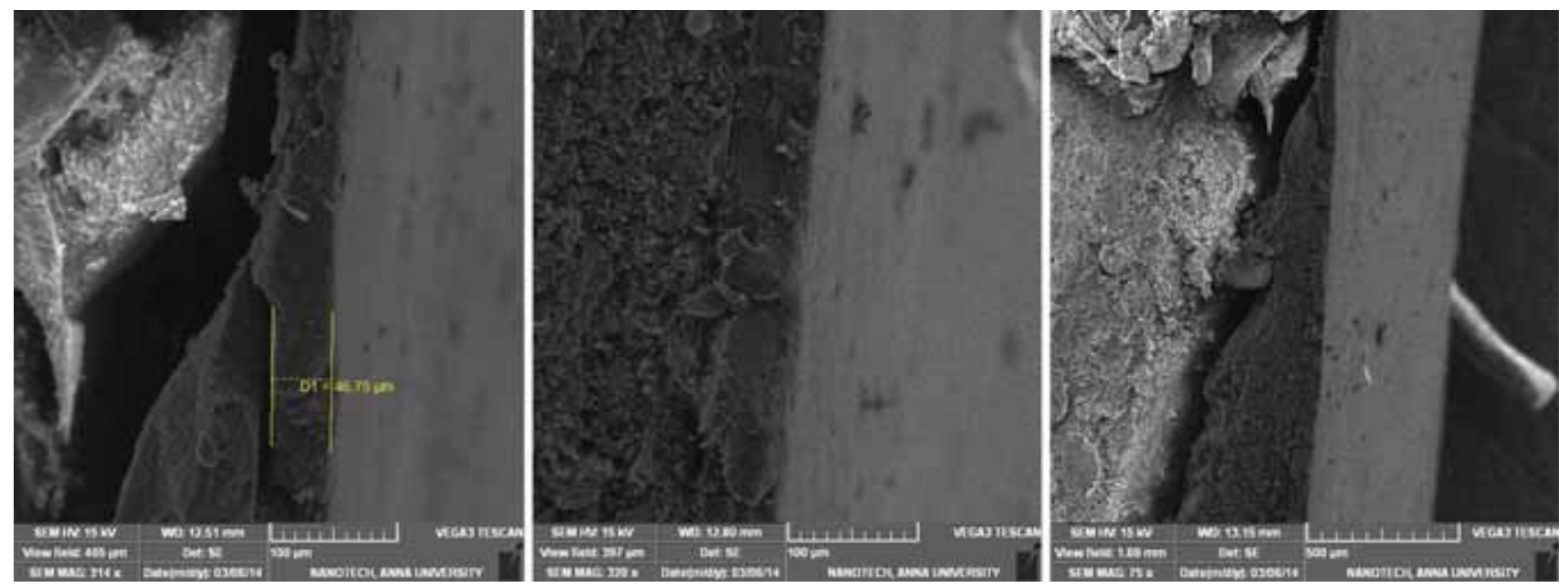

Figure 5. SEM images of PU coating thickness of $180 \mu \mathrm{m}$ on 40:60 invigorate wear out surfaces

of coir polymers results in significant improvement in tensile and flexural properties of the composites. The coefficient of friction, frictional force, applied load, wear volume, and wear rate are calculated [14]. There is an improvement in the interfacial adhesion between the matrix and coating and hence the mechanical properties, which attributes to high strength cellulosic composite. SEM observations allowed highlighting the different morphology of the surface [15]. The similarity and affinities are perhaps greatest in SEM images, which they differ principally. Lianjie Maa et al [16] developed a model that can be used to predict the surface roughness in the quick point grinding of ceramics. The initial roughness of the samples plays an important role considering the mar resistance of the coatings. It was mentioned that the hydrophobicity and tensile strength increases, but flexibility decreases with increase in the $\mathrm{NCO} / \mathrm{OH}$ ratio [17]. Higher roughness values correspond to a more limited gloss reduction [18].

\subsection{Wear test results: before (PU) coating}

The restorations can be tempered in composites. These materials tempered with heat and light have, at least initially, an enhanced degree of cure, which improves their physical properties, including wear resistance. The wear loss is calculated for various fiber and resin blends before coating as listed as follows and the weight loss is shown in table 2 .

(a) The wear loss is low at $0.012 \mathrm{~g}$ on $35: 75 \mathrm{fiber} / \mathrm{resin}$.

(b) The wear loss is medium at $0.021 \mathrm{~g}$ on $25: 75$ fiber/ resin.

(c) The wear loss is high at $0.048 \mathrm{~g}$ on $45: 55 \mathrm{fiber} / \mathrm{resin}$.
Table 2. Wear loss of uncoated specimen.

\begin{tabular}{lccc}
\hline Composites & $\begin{array}{c}\text { Weight } \\
\text { before }(\mathrm{g})\end{array}$ & $\begin{array}{c}\text { Weight } \\
\text { after }(\mathrm{g})\end{array}$ & $\begin{array}{c}\text { Weight } \\
\text { loss }(\mathrm{g})\end{array}$ \\
\hline $\begin{array}{l}25 \% \text { of fiber and } 75 \% \\
\text { of resin }\end{array}$ & 2.667 & 2.646 & 0.021 \\
$\begin{array}{l}35 \% \text { of fiber and } 65 \% \\
\text { of resin }\end{array}$ & 2.830 & 2.818 & 0.012 \\
$\begin{array}{l}45 \% \text { of fiber and } 55 \% \\
\text { of resin }\end{array}$ & 2.901 & 2.949 & 0.048 \\
\hline
\end{tabular}

Table 3. Wear loss of a coated specimen.

\begin{tabular}{lccc}
\hline Composites & $\begin{array}{c}\text { Weight } \\
\text { before }(\mathrm{g})\end{array}$ & $\begin{array}{c}\text { Weight } \\
\text { after }(\mathrm{g})\end{array}$ & $\begin{array}{c}\text { Weight } \\
\text { loss }(\mathrm{g})\end{array}$ \\
\hline $\begin{array}{l}25 \% \text { of fiber and } 75 \% \\
\text { of resin }\end{array}$ & 2.672 & 2.663 & 0.009 \\
$\begin{array}{l}35 \% \text { of fiber and } 65 \% \\
\text { of resin }\end{array}$ & 2.835 & 2.829 & 0.006 \\
$\begin{array}{l}45 \% \text { of fiber and } 55 \% \\
\text { of resin }\end{array}$ & 2.905 & 2.949 & 0.044 \\
\hline
\end{tabular}

\subsection{Wear test results: after (PU) coating}

The wear loss is calculated for the various fiber and resin blends after coating as listed as follows and the weight loss is shown in table 3 .

(a) The wear loss is low at $0.006 \mathrm{~g}$ on $35: 75$ fiber/resin, $120 \mu \mathrm{m}$ PU-coated specimen.

(b) The wear loss is medium at $0.009 \mathrm{~g}$ on $25: 75$ fiber/ resin, $60 \mu \mathrm{m}$ PU-coated specimen.

(c) The wear loss is high at $0.044 \mathrm{~g}$ on $45: 55 \mathrm{fiber} / \mathrm{resin}$, $180 \mu \mathrm{m}$ PU-coated specimen. 
The PU coatings are good in mechanical properties due to its high cross-linking levels. The property of the sample is improved by surface treatment with PU on the bond strength and micro tensile testing. The various combinations of fiber with the resin is listed in table 3. It was observed that the weight loss is more in the optimal combination of $45 \%$ fiber and $55 \%$ resin.

The wear behavior of different compositions of coconut fiber has been evaluated at different combinations of resins, and was evaluated at different sliding velocities from 0.8 to $3 \mathrm{~m} / \mathrm{s}$. SEM has been used to determine the temperature and wear rate of worn surface features. The result shows that the wear behavior of coconut fiber composite is due to the cellulose and lignin compositions. Under less load conditions the major wear loss was due to oxidation and abrasive wear. Conversely, the higher wear loss due to adhesive wear mechanism becomes a dominating factor.

\subsection{Wear rate $(K)$ of wear test before and after coating (PU)}

The increase in the applied load decreases the wear rate at higher speeds. Yousif et al [19] stated that the reduction in the wear rate with increase in applied load is due to the increase in contact area at the greater loads than the lower applied loads. The abrasive wear behavior of glass fiber reinforced polyester composites differs at various speeds, particle size, applied load, etc. [14]. The wear rate (K) calculated for the specimens of three different combinations before coating and after coating is listed in table 4 .

\section{Scratch test results before and after coating}

Polymers are designed with good scratch visibility resistance, which requires extensive knowledge about scratch deformation mechanisms and their propensity for light scattering, as elaborated by Han Jianga et al [20]. The specimen prepared is subjected to scratch test. Scratch test was conducted using reciprocating scratch testing instrument (ASTM G171) standard. A specimen of size $25 \mathrm{~mm} \times 15 \mathrm{~mm} \times 5 \mathrm{~mm}$ is allowed to be scratched with a pin of $6 \mathrm{~mm}$ diameter $\times 6 \mathrm{~mm}$ length. The testing

Table 4. Wear rate $(\mathrm{K})$.

\begin{tabular}{lcc}
\hline Composites & $\begin{array}{c}\text { Uncoated specimen } \\
\left(\mathrm{m}^{3} / \mathrm{Ncm}\right)\end{array}$ & $\begin{array}{c}\text { Coated specimen } \\
\left(\mathrm{m}^{3} / \mathrm{Ncm}\right)\end{array}$ \\
\hline $\begin{array}{l}25 \% \text { of fiber } \\
75 \% \text { of resin }\end{array}$ & $1.08 \times 10^{-5}$ & $3.13 \times 10^{-6}(60 \mu \mathrm{m})$ \\
$35 \%$ of fiber & $6.1 \times 10^{-6}$ & $2.09 \times 10^{-6}(107 \mu \mathrm{m})$ \\
$65 \%$ of resin & $2.48 \times 10^{-5}$ & $1.49 \times 10^{-5}(180 \mu \mathrm{m})$ \\
$45 \%$ of fiber & & \\
$55 \%$ of resin & & \\
\hline
\end{tabular}

parameters are load at $9.8 \mathrm{~N}$, speed at $10 \mathrm{~mm} / \mathrm{s}$ to and fro, and time at $15 \mathrm{~min}$. Surface roughness values are obtained before and after the scratch test and analyzed. As surface roughness is an important parameter to assess the quality of composites, it is decreased with an increase of surface quality. The surface roughness values ( $\mathrm{Ra}$ ) of coated specimens before and after coating that show a moderate change, as displayed in table 5 .

In this paper, fuzzy logic is first used in surface roughness. On the basis of coating thickness and fiber content, the surface roughness and wear rate are practiced through fuzzy logic approach in decision making. As the fuzzy logic provides a basis for approximate reasoning [2, 21], that is, a mode of reasoning that is not exact, it offers a more realistic framework for human reasoning than the traditional twovalued logic.

Fuzzy logic is widely used in decision-aided systems because it offers many advantages over other traditional decision-making systems [22, 23]. The fuzzy decision support systems can easily deal with incomplete and imprecise knowledge applied to either linear or nonlinear problems [24, 25]. The hydrophobicity and tensile strength increase but flexibility decreases with increasing the $\mathrm{NCO} / \mathrm{OH}$ ratio [17]. A binary coding has been used that represents the fuzzy rules base with a limited resolution on the predefined range. As fuzzy logic enables to extract benefits from all the combination methods the required goals can be achieved easily.

\section{Optimization using fuzzy logic programming}

\subsection{Fuzzy logic system}

A fuzzy logic system (FLS) can be defined as the nonlinear mapping of an input data set to a scalar output data. It was pointed out that the fuzzy clustering deals with interval partitioning using time series forecasting [26]. It also explores a framework that consists of partitioning the universe of discourse, fuzzy sets, fuzzified time series and

Table 5. Compositions_-surface roughness value (Ra) before and after coating.

\begin{tabular}{lccc}
\hline & $\begin{array}{c}\text { Surface } \\
\text { roughness } \\
(\mathrm{Ra}) \text { before } \\
\text { coating }(\mu \mathrm{m})\end{array}$ & $\begin{array}{c}\text { Surface } \\
\text { roughness } \\
\text { value }(\mathrm{Ra}) \text { after } \\
\text { coating }(\mu \mathrm{m})\end{array}$ & $\begin{array}{c}\text { Increase in } \\
\text { surface } \\
\text { roughness } \\
\text { value }(\mathrm{Ra}) \\
(\mu \mathrm{m})\end{array}$ \\
\hline $\begin{array}{l}\text { Compositions } \\
75 \% \text { of fiber }\end{array}$ & 0.382 & 0.266 & 0.116 \\
$35 \%$ of fiber & 0.66 & 0.53 & 0.13 \\
$65 \%$ of resin & & 0.703 & 0.125 \\
$45 \%$ of fiber & 0.828 & & \\
\hline $55 \%$ of resin & & &
\end{tabular}


forecasting. The rule-based approach to the fuzzy logic techniques considers imprecise value language as a set of rules that link to the finite conclusions.

A FLS consists of four main parts.
(a) Fuzzier
(b) Rules
(c) Inference engine
(d) Defuzzier

A crisp set of input data is gathered and converted to a fuzzy set using fuzzy linguistic variables, fuzzy linguistic terms, and membership functions. This step is known as fuzzification. Later, an inference is made based on a set of rules. Lastly, the resulting fuzzy output is mapped to a crisp output using the membership functions, in the defuzzification step. The FLS flow chart is showed clearly in Chart 1.

\subsection{Linguistic variables}

Linguistic variables are the input or output variables of the system whose values are words or sentences from a natural language, instead of numerical values. A linguistic variable is generally decomposed into a set of linguistic terms.

\subsection{Membership functions}

Membership functions are used in the fuzzification and defuzzification steps of an FLS to map the nonfuzzy input values to fuzzy linguistic terms and vice versa. A membership function is used to quantify a linguistic term [25].

\subsection{Fuzzy rules}

In an FLS, a rule base is constructed to control the output variable. A fuzzy rule is a simple IF-THEN rule with a condition and a conclusion. The database and rule base of FLC is used to predict the surface roughness of the material. As there are three input variables of FLC (coating thickness, fiber content, and surface roughness) and each of these inputs has three different values within range, there could be a total of $2 \times 3 \times 3=18$ rules (table $6 a, b$ ). The fuzzy logic approach for the classification of data is applied to a fuzzy rule base to incorporate expert opinion.

The expert estimation is initially fixed to classify the coating thickness and fiber content. IF coating thickness is low AND fiber content is low THEN wear rate and surface roughness is low. A fuzzy set A is defined by a membership function $\mu \mathrm{A}$ from the universe of discourse $\mathrm{Xi}$. The potential variable $\mathrm{X} \alpha=[0,1]$ for the values $\alpha$ and with the closed unit interval $[0,1]$. The $\mu \mathrm{A}(\mathrm{x})$ is interpreted as a degree of membership of $\mathrm{x}$ in $\mathrm{A}$. The linguistic variables and their representation as fuzzy sets are shown as follows.

The surface finish values of attributes need to be fuzzified and defuzzified. The fuzzification is done by
Table 6. Fuzzy rules.

(a)

Coating thickness $(\alpha)$ Fiber content $(\beta)$ Decision on wear rate

\begin{tabular}{lcc}
\hline Low & Low & Low \\
Medium & Low & Medium \\
High & Low & High \\
Low & Medium & Low \\
Medium & Medium & Medium \\
High & Medium & High \\
Low & High & Medium \\
Medium & High & Medium \\
High & High & High \\
\hline
\end{tabular}

(b)

Coating thickness Fiber content Decision on surface roughness

\begin{tabular}{lcc}
\hline Low & Low & Low \\
Medium & Low & Low \\
High & Low & High \\
Low & Medium & Medium \\
Medium & Medium & Medium \\
High & Medium & Medium \\
Low & High & Medium \\
Medium & High & Medium \\
High & High & High \\
\hline
\end{tabular}

developing a fuzzy set and fuzzy rule base (18 rules). The defuzzification process is done based on the crisp value of coating thickness and fiber content, which is extracted from the fuzzy set as a representative value.

\subsection{Wear rate and surface coating optimization using fuzzy logic}

The correlation between wear rate and surface coating is customized. Surface roughness is one of the most important factors in assessing the quality of ground components $[3,13]$. As many attempts have been made in customizing mechanical and tribological properties, the wear properties play a major role in the polymeric composite research [27]. It has been demonstrated that the fuzzy basic functions as a nonlinear approximator [25]. The hardness property and compression strength play a main role in controlling the abrasive wear [22, 28]. The higher the compression strength, the lower is the specific wear rate.

In this paper, a method of automatic fuzzy logic control is being adapted to optimize the coating. Fuzzy logic has been developed for various systems or processes based on their potential in solving complex problems. In this connection, works of Takagi and Sugeno [29] are worth mentioning. The coating thickness and fiber content are the two main variables considered as input variables.

Depending on these two variables the output is generated and predicted using the results of experimental data obtained from wear rate and surface roughness value. 


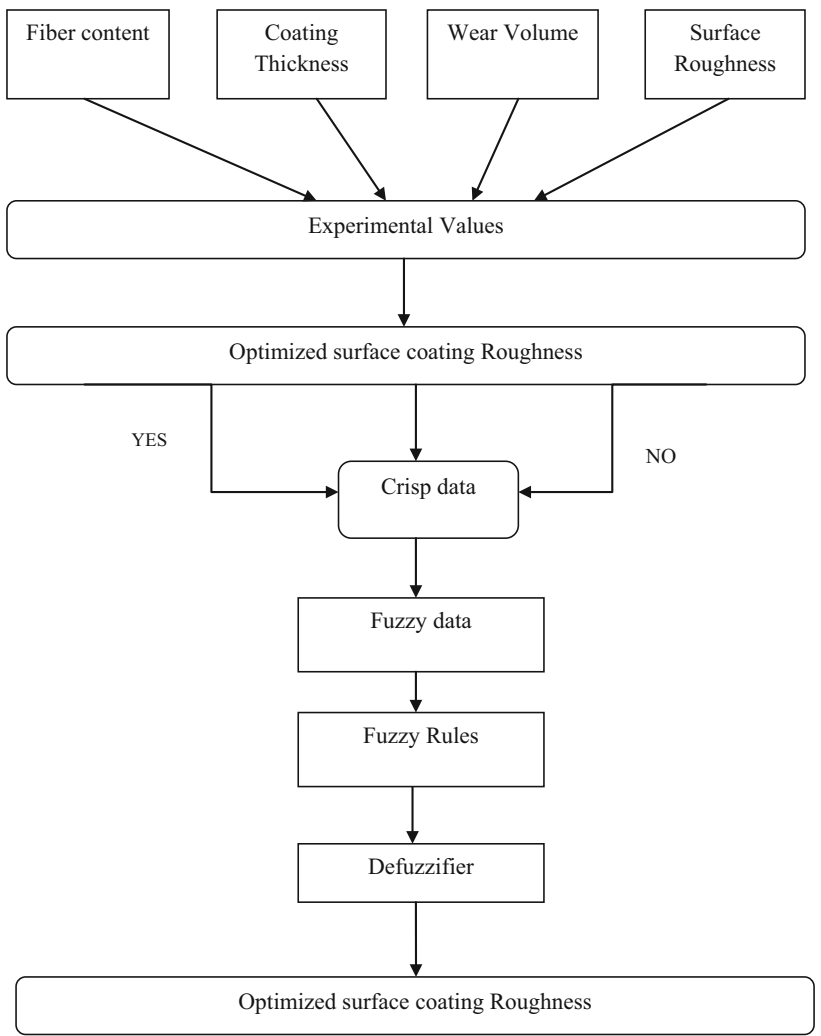

Figure 6. Fuzzy logic flow chart using MATLAB.

Figure 6 shows the schematic representation of fuzzy logic used.

Assessing the surface quality of a product by visual method is troublesome, hence decision-making methods such as fuzzy logic is being used to facilitate and improve the process [22].

Rule-based approach and rule set representations have the desirable property of being able to adjust the size of data based on the complexity of problem or data. Fuzzy rule effectively reduces the search space by permitting only evaluation of general rules. The fuzzy rules and fuzzy set membership functions are necessary for controlling complex systems with high-dimensional input/output data sets.

A multivalued logic derived from fuzzy set theory deals with reasoning that is approximate rather than precise. The fuzzy variables have a membership value of not only 0 or 1 but also a value between 0 and 1 . It provides approximate reasoning that is not accurate. It gives a more realistic methodology for human reasoning than a traditional twovalued logic. Levent Aydin and Secil Artem (2011) uses MATLAB to obtain the fitness functions of optimization problems. They also identified the stress distributions of the optimized composites through the thickness of the laminates subjected to mechanical and thermal loadings. The MATLAB software is being used in this work to create a fuzzy logic system, which creates membership functions that are used in the fuzzification and defuzzification steps. This maps the nonfuzzy input values to fuzzy linguistics terms. The strength and stiffness properties of sandwich panels are optimized by changing the weight critical applications. Similarly, the sandwich panels made in the form of a honeycomb core are tested for strength and stiffness properties. The optimization of these parameters is a crucial area of research. A very close experimental and theoretical value of stiffness and strength was found [30].

This paper uses MATLAB to program the code. The two criteria, fiber content and coating thickness are used as input, which represents an experimental data.

Pace 1: fiber content, coating thickness values are fed as an input in FLS, form of membership function that represent experimental data obtained.

Pace 2: wear volume and surface roughness values are fed as an output in FLS, form of membership function that represent experimental data obtained.

Pace 3: Fuzzy rules are generated and fed into FLS to give optimized wear rate and surface coating optimization.

Pace 4: Crisp data stores if-then Fuzzy rules, which generates output from the input fed into FLS.

Pace 5: Defuzzifier generates the output from the input fed to give optimized results.

\subsection{Model calculation for medium wear rate}

The centroid of area (COA) is adopted for defuzzification. A defuzzification operator is developed for transforming an output membership function into a single crisp output value. This defuzzification calculates the membership value of the output, corresponding to each of the 18 sets of rules.

Lowval $=2.16:$ midval $=2.66:$ highval $=3.16$

Midlow $=$ midval-lowval

$=2.66-2.16$

$=0.5$

Highmid $=$ highval-midval

$=3.16-2.66=0.5$

\subsection{Using command in MATLAB for fuzzy logic} programming

fis $=$ readfis ('surface roughness optimization.fis');

out $=$ evalfis $([90.5-50]$, fis $)$

out $=$ Columns 1 through $5-1.00001 .0750 \quad 0.0585$

2.6685 (medium wear rate)

0.1205 (medium surface roughness)

Column $6-0.1230$.

Similarly, low, medium, high wear rate, and surface coating optimization are predicted using Fuzzy logic in MATLAB. 


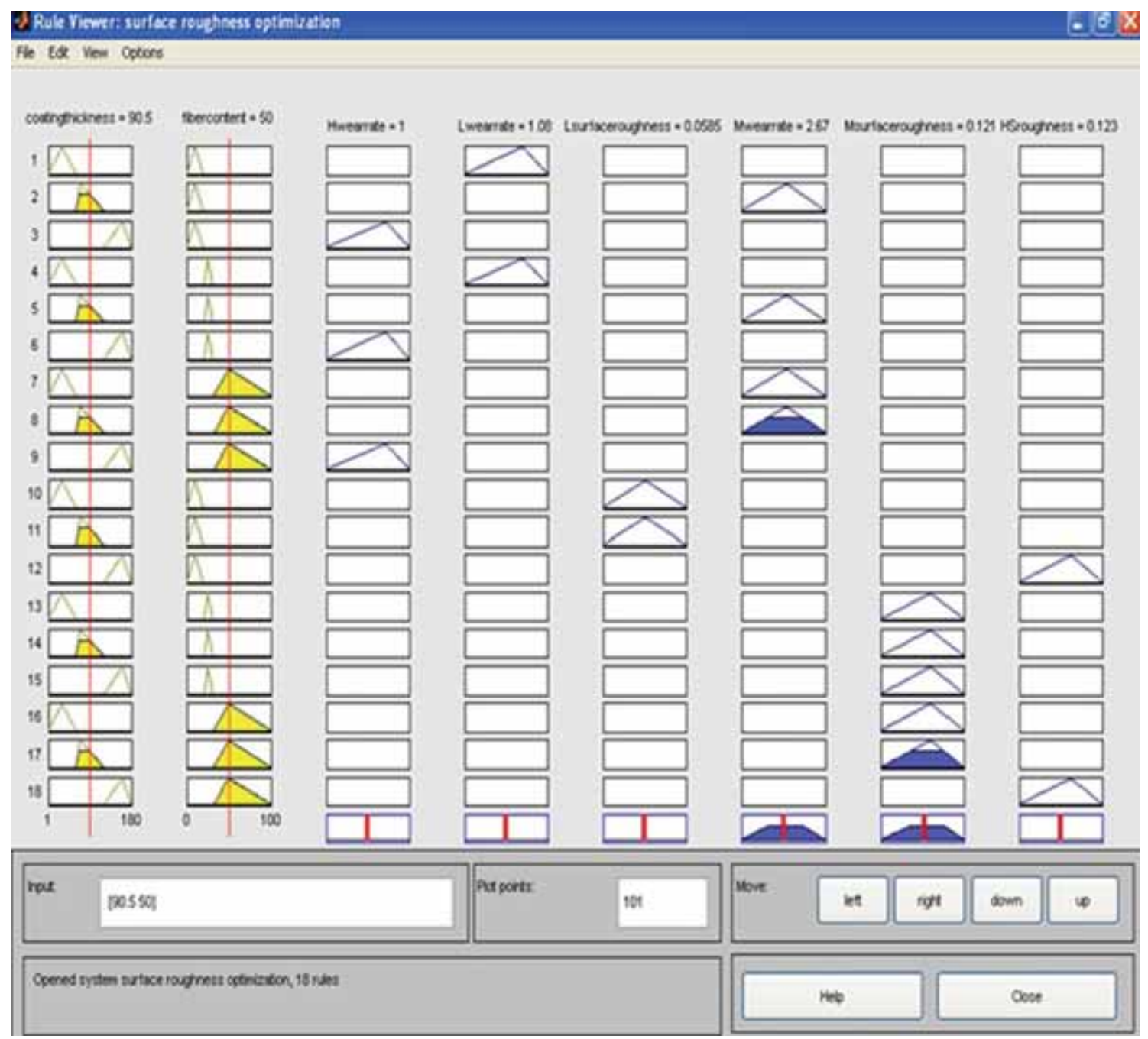

Figure 7. Rule viewer.

\section{Conclusion}

MATLAB 7 software was used in the study to analyze the surface coating optimization inspection results by fuzzy logic method. Triangular membership functions were employed for the fuzzy subsets. The Mamdani fuzzy rules relating the input variables to the output variables were created. The rating scale for input variables (coating thickness and fiber content) was of three levels: high, medium, and low. The rating scale for output variable (surface roughness) was, however, of three levels: high, medium, and low. The model was run based on the 18 decision rules created during the application, as follows.

Optimization using Fuzzy logic with two variables:

(a) Coating thickness

(b) Fiber content
To obtain the output, namely:

(c) Wear rate (high, medium, low)

(d) Surface roughness (high, medium, low)

Results obtained using MATLAB are displayed using Rule viewer shown in figure 7.

One value of coating thickness and fiber content can satisfy only two of the rules, namely, wear rate and surface roughness, which can be of the range low, medium, and high.

\subsection{Rules predicted using experimental values}

IF feature coating thickness is low AND feature fiber content is medium THEN Wear rate class = medium. The rules can be combined in a table called rule base.

1. If coating thickness is low and fiber content is low, then the wear rate is low. 
2. If the coating thickness is medium and the fiber content is low, then the wear rate is medium.

3. If the coating thickness high and the fiber content is low, then the wear rate is high.

4. If the coating thickness is low and the fiber content is medium, then wear rate is low.

5. If the coating thickness is medium and the fiber content is medium, then the wear rate is medium.

6. If the coating thickness is high and the fiber content is medium, then the wear rate is high.

7. If the coating thickness is low and the fiber content is high, then the wear rate is medium.

8. If coating thickness is medium and the fiber content is high, then the wear rate is medium.

9. If the coating thickness is high and the fiber content is high, then the wear rate is high.

10. If the coating thickness is low and the fiber content is low, then the surface roughness is low.

11. If the coating thickness is medium and the fiber content is low, then the surface roughness is low.

12. If the coating thickness is high and fiber content is low, then the surface roughness is high.

13. If the coating thickness is low and fiber content is medium, then the surface roughness is medium.

14. If the coating thickness is medium and fiber content is medium, the surface roughness is medium.

15. If the coating thickness is high and the fiber content is medium, then the surface roughness is medium.

16. If the coating thickness is low and the fiber content is high, then the surface roughness is medium.

17. If the coating thickness is medium and the fiber content is high, then the surface roughness is medium.

18. If the coating thickness is high and the fiber content is high, then the surface roughness is high.

Sample input values:

Coating thickness, fiber content: [28.09 34.87]

Output: Medium wear rate of $2.66 \mathrm{~m}^{3} / \mathrm{Ncm}$

Medium surface roughness of $0.121 \mu \mathrm{m}$

Fuzzy logic command in MATLAB:

fis = readfis ('surface roughness optimization.fis');

out $=$ evalfis $([28.09-34.87]$, fis $)$

out $=$ Columns 1 through $5-1.00001 .07500 .05852 .66$

(medium wear rate) 0.121 (medium surface roughness)

Column $6-0.1230$.

From these comparative results, it can be inferred that the fuzzy approach performed better assessment on surface coating quality. It also offers the knowledge on defects and its categories on the quality level of the composites. Different membership functions and several other attributes can also be added to the list of surface quality attributes for future applications. Assessing the quality of surface roughness is quite ambiguous and difficult, so it makes a clear quality distinction among the composites. The visual inspection of coconut fiber is quite common in checking the quality of the product. Hence, the use of fuzzy logic would facilitate the composite making process quite logical and simple.

This fuzzy logic approach helps in converting optimization of the various surface parameters and irregularities into simple performance parameter. Hence, the performance parameters such as coating thickness and wear rate can be improved through this proposed work. The sturdiest combination of process parameters has been identified through this fuzzy logic to predict the performance of parameters. Hence, fuzzy logic would be helpful in improving the process. The model developed in this paper is satisfactory in terms of measurement of various factors of surface finish of these newly developed composites.

\section{References}

[1] Harish S, Peter Michael D, Bensely A, Mohan Lal D and Rajaduraic A 2009 Mechanical property evaluation of natural fiber coir composite. Mater. Charact. 60(1): 44-49

[2] Thrift P 1991 Fuzzy logic synthesis with genetic algorithms. In: Proceedings of the Fourth International Conference on Genetic Algorithms. San Diego, CA, pp. 509-513

[3] Aydin L and Artem H S 2011 Comparison of stochastic search optimization algorithms for the laminated composites under mechanical and hygrothermal loadings. J. Reinf. Plast. Compos. 30(14): 1197-1212

[4] Tielemansa M and Roosea P 2012 Multiphase coatings from complex radiation curable polyurethane dispersions. J. Prog. Org. Coat. 75: 560-568

[5] Verma D and Gope P C 2013 Coir fiber reinforcement and application in polymer composites. Environ. Sci. 4(2): 263-276

[6] Khedari J, Suttisonk B, Pratintong N and Hirunlabh J 2002 New lightweight composite construction materials with low thermal conductivity. J. Chem. Compos. 23: 65-70

[7] Eghbal Jahromi P, Shojaei A and Reza Pishvaie M 2004 Predication and optimization of cure cycle thin fiber-reinforced composite parts using dynamic artificial neural networks. SAGE Publications

[8] Gite V V, Mahulikar P P, Hundiwale D G and Kapadi U R 2004 Polyurethane coatings using trimer of isophorone diisocyanate. J. Sci. Ind. Res. 63: 348-354

[9] Karnani R, Krishnan M and Narayan R 1997 Bio fiber-reinforced polypropylene composites. Polym. Eng. Sci. 37 (2): 476-483

[10] Asakawa Y, Takahashi H, Kobayashi M and Iwasaki N 2013 Effect of components and surface treatments of fiber-reinforced composite posts on bond strength to composite resin. J. Mech. Behav. Biomed. Mater. 26: 23-33

[11] Guohua W, Bharat B and Peter M T 2005 Nano chemical characterization of human hair using nano indentation and SEM. Ultramicroscopy 105: 248-66

[12] Goldstein J, Newbury D E, Joy D C, Lyman C E, Echlin P, Lifshin E, Sawyer L C and Michael J R 2003 Scanning electron microscopy and X-ray microanalysis. Kluwer/Plenum, New York, 689 
[13] Gowda T M, Naidu A C B and Chhaya R 1999 Some mechanical properties of untreated jute fabric reinforced polyester composites. Compos.: Part A 30: 277-284

[14] Chand N, Naik A and Neogi S 2000 Three-body abrasive wear of short glass fibre polyester composite. Wear 242: $38-46$

[15] Aireddy H and Mishra S C 2013 Sem-analysis and effects of wear test. J. Mech. Behav. Surf. Mater. 36: 13-33

[16] Lianjie Maa B N and Gong Y 2014 Study on surface roughness model and surface forming mechanism of ceramics in quick point grinding. J. Mach. Tools Manuf. 77: 82-92

[17] Mishra A K, Narayan R and Raju K V S N 2012 Structureproperty correlation study of hyper branched polyurethaneurea (HBPU) coatings. J. Prog. Organic Coat. 74(3): 491-501

[18] Scrinzi E, Rossi S, Deflorian F and Zanella C 2011 Evaluation of aesthetic durability of waterborne polyurethane coatings applied on wood for interior applications. Prog. Organic Coat. 72: 81-87

[19] Yousif B F and El-Tayeb N S M 2010 Wear characteristics of thermoset composite under high stress three-body abrasive. Tribol. Int. 43(12): 2365-2371

[20] Jianga H and Browninga R L 2010 Quantitative evaluation of scratch visibility resistance of polymers. J. Appl. Surf. Sci. 256: 6324-6329
[21] Balazinski M, Bellerose M and Czogala E 1994 Application of fuzzy logic techniques to the selection of cutting parameters in machining processes. Fuzzy Sets Syst. 61: 301-317

[22] Kumru M 2013 Assessing the visual quality of sanitary ware by fuzzy logic. J. Appl. Soft Comput. 13: 3646-3656

[23] Rowlands H and Wang L R 2000 An approach of fuzzy logic evaluation and control in SPC. Qual. Reliab. Eng. Int. 16(2): 91-98

[24] Baron L, Achiche S and Balazinski M 2001 Fuzzy decisions system knowledge base generation using a genetic algorithm. Int. J. Approx. Reason. 28(2-3): 25-148

[25] Mendel J M 1995 Fuzzy logic systems for engineering: a tutorial. Proc. IEEE 83: 345-377

[26] Li S-T, Cheng Y-C and Lin S-Y 2008 A FCM-based deterministic forecasting model for fuzzy time series. J. Comput. Math. Appl. 56: 3052-3063

[27] Sanjay Kindo J, Patnaik A and Biswas S 2011 Effect of fiber length on mechanical behavior of coir fiber reinforced epoxy composites. J. Fibers Compos. 12(1): 73-78

[28] Medalia A I 1980 On structure property relations of rubber. In: Proceedings of the International Conference, Kharagpur, India, 13

[29] Sugeno M and Kang G T 1988 Structure identification of fuzzy model. Fuzzy sets Syst. 28: 15-33

[30] Murthy O, Munirudrappa N and Srikanth L 2006 Strength and stiffness optimization studies on honeycomb core sandwich panels. J. Reinf. Plast. Compos. 25(6): 663-671 